\title{
Propuesta de esquematización de la exclusión espacial. Caso Monterrey, México ${ }^{1}$
}

\author{
Schematic proposal of spatial exclusion. Case Monterrey, Mexico
}

\section{Cómo citar:}

Padilla Herrera, D., 2020. Propuesta de esquematización de la exclusión espacial. Caso Monterrey, México. Designia, 8(1), pp.101-119.

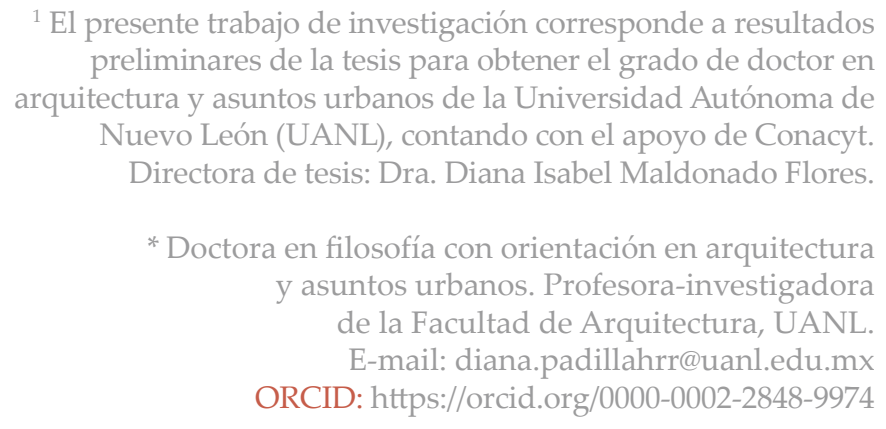

Palabras clave:

Ciudad, urbanismo,

dibujo, diferencia.

Key words:

City, urbanism, mapping,

difference

Recibido: 05/02/2020

Aceptado: 27/03/2020

Resumen:

Los mapas, como medio de representación gráfica, muestran lo que se quiere ver de la ciudad, como esquemas que visibilizan estructuras urbanas integradas, pero que a su vez ocultan otras. La exclusión -desde un punto de vista territorial- pasa desapercibida por las dinámicas sociales, por lo que recuperar el topos se convierte en algo fundamental. Este artículo propone una nueva esquematización en torno a la exclusión, a través del desarrollo del concepto de exclusión espacial, el cual permite identificar los diversos procesos espaciales 
que producen exclusión. Así, en la ciudad existen múltiples fuerzas que no son identificadas, por lo que la esquematización de la exclusión espacial se convierte en una alternativa de graficación para visibilizar las fuerzas que interactúan en el ambiente construido. Lo anterior plantea nuevas posibilidades de abordaje para los fenómenos espaciales de las ciudades contemporáneas.

\section{Abstract:}

The maps, as a mean of graphic representation, show only one reality of the city, as schemes that integrate urban structures, but in turn, hide others. Exclusion -from a territorial point of view- undergoes unnoticed by social dynamics, so recovering the territoriality becomes fundamental. This article proposes a new schematization around exclusion, where the concept of spatial exclusion is developed, which allows the identification of spatial processes that produce exclusion. So, in the city exists multiple forces that are not identified; therefore, the schematization of spatial exclusion becomes an alternative of graphing to make visible the forces that interact in the built environment. This raises new possibilities of approaching the spatial phenomena of contemporary cities. 


\section{INTRODUCCIÓN}

El presente artículo forma parte de los resultados obtenidos en la tesis doctoral Los espacios otros en las ciudades latinoamericanas. Redefinición de la inclusión desde la exclusión espacial (Padilla, 2019), en donde se redefine la relación entre inclusión y exclusión, explorando la construcción de mapas como herramienta de visibilización de lo otro. Así, este artículo propone otra manera de graficar el espacio urbano-arquitectónico.

El dibujo apoya las nuevas propuestas de esquematización, ya que, durante siglos, ha sido utilizado como herramienta de expresión gráfica, y a través de imágenes, símbolos y signos se representan ideas y conceptos que ayudan a entender la realidad. En arquitectura, el dibujo comienza en dos dimensiones, para mostrar espacios mediante proyecciones ortogonales (planta, sección y alzado); posteriormente se transforma en dibujos axonométricos, que permiten una comprensión tridimensional, ampliando el entendimiento del entorno (Saniz, 1990). La morfología urbana se expone partir de mapas que identifican los elementos naturales y artificiales que integran la ciudad; de este modo, el dibujo se convierte en una herramienta de interpretación que permite nuevas aproximaciones gráficas dentro de los análisis urbanos.

Las herramientas que se utilizan actualmente para la captura de información muestran una realidad parcial que convierte el dibujo en un lenguaje monosémico (Saniz, 1990), por lo que los mapas convencionales constituyen solo una parte de la imagen.

El presente artículo se estructura en cuatro apartados diferentes: el primero inicia con la separación entre ciudad y no ciudad, es decir, se establece la diferencia entre espacios integrados a la dinámica urbana y aquellos que quedan relegados de ella; posteriormente se reflexiona en torno a la exclusión social y su transformación hacia el concepto espacial. A manera de conclusiones y resultados, se ilustra el concepto de exclusión espacial, a través de esquemas que identifican las múltiples fuerzas que intervienen en el proceso de exclusión de la ciudad contemporánea; mediante el dibujo, se establecen nuevas alternativas gráficas para visibilizar la exclusión. Por último, se muestran las referencias de apoyo. 


\section{De la ciudad a la no ciudad}

Los primeros asentamientos humanos representan un sistema propio de organización territorial, donde los espacios se designan de manera estratégica dependiendo de su funcionalidad, clase social, estatus político, entre otros. Lewis Mumford explica que el nombre de ciudad se asigna cuando en una superficie limitada se integran espacios como el santuario, la fuente, el mercado, la fortaleza, entre otros. Así, la ciudad es el resultado de un proceso lineal que la consolida hasta alcanzar un alto nivel de desarrollo, teniendo como característica el almacenaje y transmisión de los bienes de la civilización (Mumford, 1989). Para este autor, la ciudad se define a partir de la organización y planeación del espacio, en una distribución que busca priorizar aspectos económicos, políticos y sociales dentro de la misma; sin embargo, ¿qué sucede con los espacios que no alcanzan tales características? La representación de la ciudad consolida una imagen de poder que evita mostrar su oposición; en tal sentido, la no ciudad constituye la otra cara de la moneda, los espacios que no se muestran en los mapas o aquellas zonas que, por su origen, quedan relegadas hacia el exterior.

Para explicar la diferencia entre ciudad y no ciudad se define una línea de tiempo dividida en tres periodos distintos: pre-moderno, moderno y posmoderno, estableciendo descripciones y gráficos que muestra la ubicación de tales espacios. Las ciudades que se analizan en el periodo premoderno son la proto-ciudad (Soja, 2008), la ciudad clásica, la ciudad medieval y la ciudad renacentista. En el periodo moderno se explica la ciudad industrial; mientras que en el periodo posmoderno se muestra la ciudad contemporánea.

Los primeros mapas de la ciudad ya muestran los elementos de definición de la misma: por ejemplo, la proto-ciudad se caracteriza por establecer un núcleo urbano central a partir de la vivienda, núcleo que se convierte en el centro de poder; sin embargo, la actividad comercial (trueque), los campamentos de caza y los espacios de recolección de alimentos se establecían afuera de este centro. 
En la ciudad clásica, la vida urbana se consolidaba a partir de un centro cívico llamado la ciudadela, una estructura político-económica desde donde se trataba de disciplinar y controlar a los habitantes. La ciudadela representaba una pequeña ciudad que institucionalizó los tres poderes que hasta ahora siguen rigiendo: el poder religioso, el político y el económico. De esta manera, la vivienda quedó desplazada como origen de la ciudad, y se inició una estratificación de la población, es decir, se organizó la ciudad en clase sociales, dejando a los más desamparados en el exterior. Posteriormente, la ciudad medieval mantuvo el centro de poder heredado de las ciudades clásicas; sin embargo, el comercio adquirió un rol principal gracias a las nuevas rutas marítimas y la consolidación del mercado en el interior. Es con la muralla que se estableció una división adentro-afuera, por lo que las viviendas de clase baja quedaban afuera de esta. La muralla representaba un elemento de defensa, pero también de separación entre la ciudad y la no ciudad.

Por su parte, la ciudad renacentista se organizaba a partir de dos ejes que mostraban la división entre la alta burguesía y la clase baja: la plaza pública y los bulevares se destinaban para aquellos habitantes ilustres, mientras que la no ciudad quedaba representada en los espacios para enfermos y los hospitales de leprosos.

En el periodo moderno, la ciudad industrial priorizó una distribución radiocéntrica que transformó el centro de poder en un centro de control laboral, esto es, en un distrito de negocios; a pesar de lo anterior, la vivienda para obreros se estableció en el primer anillo cercano a las industrias y fábricas, conteniendo a los habitantes de clase social baja. Así, la zonificación separó la ciudad de manera drástica en zonas estratégicas, dependiendo de la tipología y del habitante. Por último, en el periodo posmoderno las ciudades contemporáneas evidencian una expansión mayor en comparación a la ciudad industrial; el distrito central de negocios se deslocaliza ahora, permitiendo que exista en diferentes partes. La zona de exclusión de la ciudad contemporánea se caracteriza por la aparición de asentamientos informales que buscan vivir cerca del centro laboral, surgiendo nuevas mixturas entre zonas, lo que desdibuja los límites entre el centro y la periferia. 
Identificar la organización espacial de la ciudad en distintos periodos de tiempo permite observar los espacios que la conforman, y a partir de ahí, definir la no ciudad (figura 1). Generalmente, la no ciudad se caracteriza por su poco equipamiento y falta de conectividad, así como por agrupaciones de informalidad, viviendas de interés social, zonas especiales como cárceles, espacios para enfermos, fábricas, entre otros. La configuración que adquiere la no ciudad se hace de manera paulatina y pensada desde la ciudad, identificando procesos que intensifican la diferencia, espacios otros (Foucault, 1984) que, al no ser incluidos en los mapas urbanos, invisibilizan una parte de la ciudad, es decir, reproducen más dinámicas de exclusión.
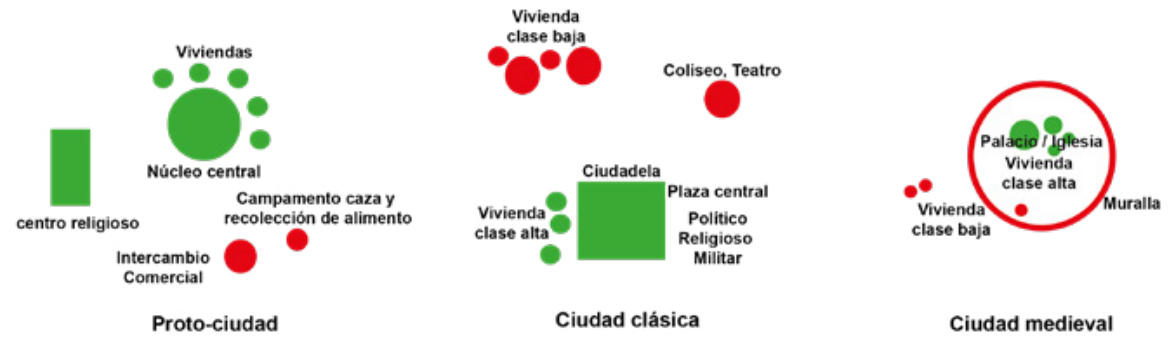

Ciudad

No Ciudad

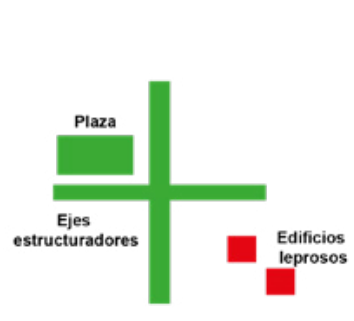

Ciudad renacentista

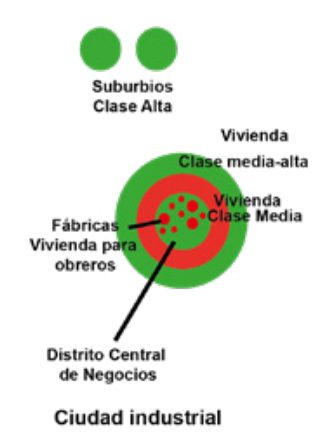

Ciudad industrial

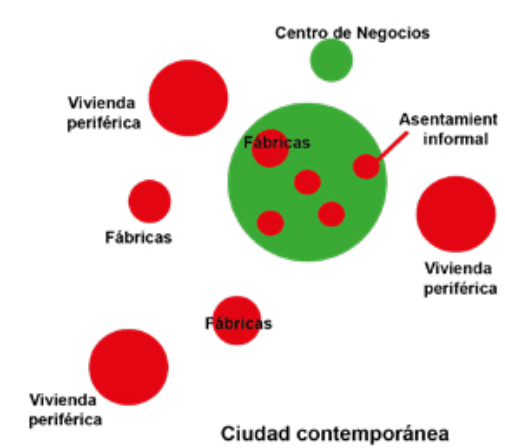

Ciudad contemporánea

Figura 1. Esquemas de representación de la ciudad y la no ciudad. 


\section{Exclusión espacial: recuperando el topos}

La exclusión como concepto ha sido analizada desde un punto de vista económico y social, donde se destacan diferencias o carencias a partir de ingresos, género, edad, escolaridad, entre otros. La mayoría de las veces, el concepto de exclusión se utiliza como sinónimo de pobreza, ya que a partir de la capacidad económica que tenga el individuo o la familia se define al pobre y no pobre (Link, 2010), lo cual, a su vez, se puede traducir en etiquetas de exclusión o inclusión.

René Lenoir (1974) estableció el término de exclusión social para explicar la ruptura y el quiebre que presentan diversas clases de personas respecto al resto de la sociedad. Para Lenoir, los enfermos mentales, ancianos, suicidas potenciales, discapacitados, niños abusados, drogadictos, delincuentes, padres-madres solteros, personas marginales, entre otros, constituyen los excluidos; en ese sentido, la exclusión es entendida a partir de una condición social, mental o económica que indica una diferencia entre las personas. Sin embargo, el concepto de exclusión se transformó cuando la Organización de las Naciones Unidas para la Educación, la Ciencia y la Cultura (Unesco) explicó que la condición de excluido surge a partir de una serie de desventajas respecto al resto de la población, por ejemplo, desde la negación de derechos civiles, sociales, políticos, económicos y culturales. Para la Unesco, los excluidos son personas en condición de extrema pobreza, desempleados, discapacitados, padres solteros, personas con problemas de salud, personas con baja autoestima, personas en situación de calle, adictos, entre otros (Bessis, s.f.).

Por otro lado, la Comisión Económica para América Latina y el Caribe (Cepal) explica que la exclusión social no solo afecta a ciertos individuos o estratos económicos, sino que pueden existir muchas maneras de alcanzar la condición de excluido (Cepal, 1998). De acuerdo con Robles (1999), la exclusión puede ser primaria o secundaria, en la medida en que la exclusión primaria expone la falta de accesibilidad a sistemas funcionales de la sociedad, mientras que la exclusión secundaria expresa una inacce- 
sibilidad a redes de interacción social, lo cual significa no tener acceso a ciertas esferas sociales (Link, 2010). La exclusión social no solo expresa una incapacidad de integración en sistemas económicos, bienes públicos y servicios básicos, sino que también considera los procesos en los que se desarrolla la sociedad.

Manuel Castells (2006) explica que la exclusión social se concibe como un proceso mediante el cual a ciertos individuos se les impide el acceso a posiciones, niveles sociales o instituciones dentro de un contexto. El autor también argumenta que la exclusión social no es una condición, sino que se transforma y varía dependiendo de las circunstancias que se vivan o tengan en un determinado momento; es decir, la exclusión es el resultado de una serie de condiciones particulares. Durante las últimas décadas, y como resultado de una nueva dinámica económica, el paisaje y la morfología urbana han cambiado (De Mattos, 2007). Así, la ciudad se ha transformado en un espacio descontrolado, que genera aglomeraciones expandidas y difusas como muestra de cambios en la organización espacial y, por lo tanto, en la vida urbana (De Mattos, 2010). El término exclusión ya no es suficiente, por lo que Saskia Sassen (2014) propone el concepto de expulsión como elemento clave para entender las nuevas configuraciones urbanas, donde diversos procesos cotidianos se vuelven tan extremos que necesitan otro análisis $\mathrm{y}$, por lo tanto, otras representaciones para su entendimiento.

Las aportaciones hechas por los autores mencionados exponen que la exclusión se transforma de condición a proceso, por lo que para la recuperación del topos se propone el concepto de exclusión espacial, como un conjunto de procesos espaciales que ocasionan exclusión, lo cual a su vez permite identificar y visibilizar los fenómenos espaciales que, de manera paulatina, encaminan a los territorios y habitantes a la expulsión. La exclusión se agudiza cada vez más en la ciudad, y las fuerzas que intervienen en dicho proceso quedan invisibilizadas en los mapas urbanos. La esquematización de la exclusión espacial expone otra manera de dibujar la exclusión, por lo que se convierte en una herramienta clave para el análisis y reflexión de la ciudad. 
Para ilustrar la exclusión espacial en Monterrey se seleccionó la colonia Independencia, espacio que históricamente constituye una zona de estigmatización y exclusión, ya que por sus características de configuración se convierte en una no ciudad. La Independencia se ubica al otro lado del río Santa Catarina ${ }^{2}$; ahí, fueron confinados los indios tlaxcaltecas después de la conquista de la ciudad, separando así a los conquistadores de los conquistados. Con el paso de los años y el crecimiento de la ciudad se constituyó el barrio San Luisito, nombre que se adoptó a raíz de los nuevos habitantes, migrantes originarios de San Luis Potosí. Ante el aumento de población, y en concordancia con los festejos por el centenario de la independencia de México, se decidió cambiar al nombre que actualmente conocemos. La Independencia representa la primera colonia ubicada afuera del centro de la ciudad, es decir, constituye la primera periferia.

La metodología de investigación de este documento se deriva del trabajo propuesto por Neil Brenner (2014), quien utiliza la teoría urbana crítica para entender los cambios dentro del paisaje urbano. El autor sustituye la unidad de análisis concéntrica por un sistema abierto multiescalar, buscando entender lo urbano como un proceso socio-espacial de crecimiento desigual en el mundo; en el modelo de organización territorial se cambia la tipología binaria por un entendimiento dialéctico, partiendo de la ciudad y su opuesto; y por último, en el modelo de larga duración del cambio histórico-geográfico se reemplaza el sistema lineal de crecimiento por un sistema discontinuo desigual del desarrollo territorial.

En primera instancia, se recolectaron relatos de los habitantes de la colonia seleccionada y, a partir de dichos relatos, se establecieron escenas. Cada escena muestra un periodo de tiempo específico, en el cual es posible observar los cambios en el territorio. En el primer mapa se describe el nodo, nivel y uso del espacio, por ejemplo: jugar fútbol en la Independencia. La primera escena, y con ella el primer mapa, establece el origen, es decir, el uso habitual del espacio; posteriormente se muestra una segunda escena y un segundo mapa, con el nombre de Transformación 1, donde se relata el primer cambio de uso del espacio; la tercera escena y el tercer mapa, llamado Transformación 2, muestran los cambios posteriores de uso del espacio. La realización de los mapas y escenas subsecuentes exhiben nombres como: Transformación 3 y Transformación 4, de modo que el número de transformaciones puede ser múltiple.

${ }^{2}$ El río Santa Catarina es un río seco, es decir, solo en época de lluvia tiene corriente de agua. 
A manera de síntesis para esta investigación, la unidad de análisis está constituida por las formas espaciales derivadas de las variantes de mediación dentro de los otros espacios; el modelo de organización territorial utiliza las superposición de territorios -resultantes de las escenas- y las múltiples fuerzas implicadas para identificar el proceso de exclusión; para el entendimiento del desarrollo territorial se utilizaron relatos de diferentes periodos de tiempo, los cuales establecieron escenas de actividades de la vida cotidiana como configuradoras del espacio; por último, el modelo de larga duración del cambio histórico geográfico es discontinuo, basado en procesos socio-espaciales. Además de la construcción de mapas, se realizó trabajo de campo, búsqueda en archivo y observación participante.

Particularmente en la Independencia, jugar fútbol constituyó una actividad cotidiana, por lo que el primer mapa de origen (figura 2) muestra que el uso del espacio se extendía más allá de la propia colonia, ya que habitantes de las colonias aledañas acudían a jugar fútbol e inscribirse en los torneos vecinales. En un principio, los vecinos jugaban en la explanada de la iglesia; sin embargo, con la construcción de la nueva basílica los vecinos se desplazaron hacia el tanque de agua ubicado en la parte superior de la colonia. El segundo mapa (figura 3) muestra cómo, después de que el terreno donde estaba ubicado el tanque de agua cerrara, los habitantes se trasladaron a jugar al río Santa Catarina y las canchas del río se convirtieron en su nueva casa; sin embargo, con la llegada del huracán Gilberto las canchas quedaron inutilizables, por lo que los habitantes nuevamente tuvieron que buscar un nuevo espacio para practicar su deporte. El tercer mapa (figura 4) expone que, después del paso del huracán Gilberto, a los habitantes se les permitió utilizar los estacionamientos de bancos y tiendas de abarrotes para practicar su deporte; sin embargo, se restringieron los horarios y días en los que podían hacerlo, por lo que los equipos se desintegraron y se eliminaron los torneos. El cuarto mapa (figura 5) muestra cómo a partir de una serie de prohibiciones y desplazamientos que sufrieron los habitantes decidieron ya no practicar fútbol, por lo que terminaron viendo los partidos solo por televisión. El último mapa (figura 6) ilustra las distintas formas de exclusión espacial. A través del dibujo se evidencia la pérdida y cambio de uso en el espacio, dando como resultado una trayectoria de exclusión donde el primer nivel lo constituye el desplazamiento. 


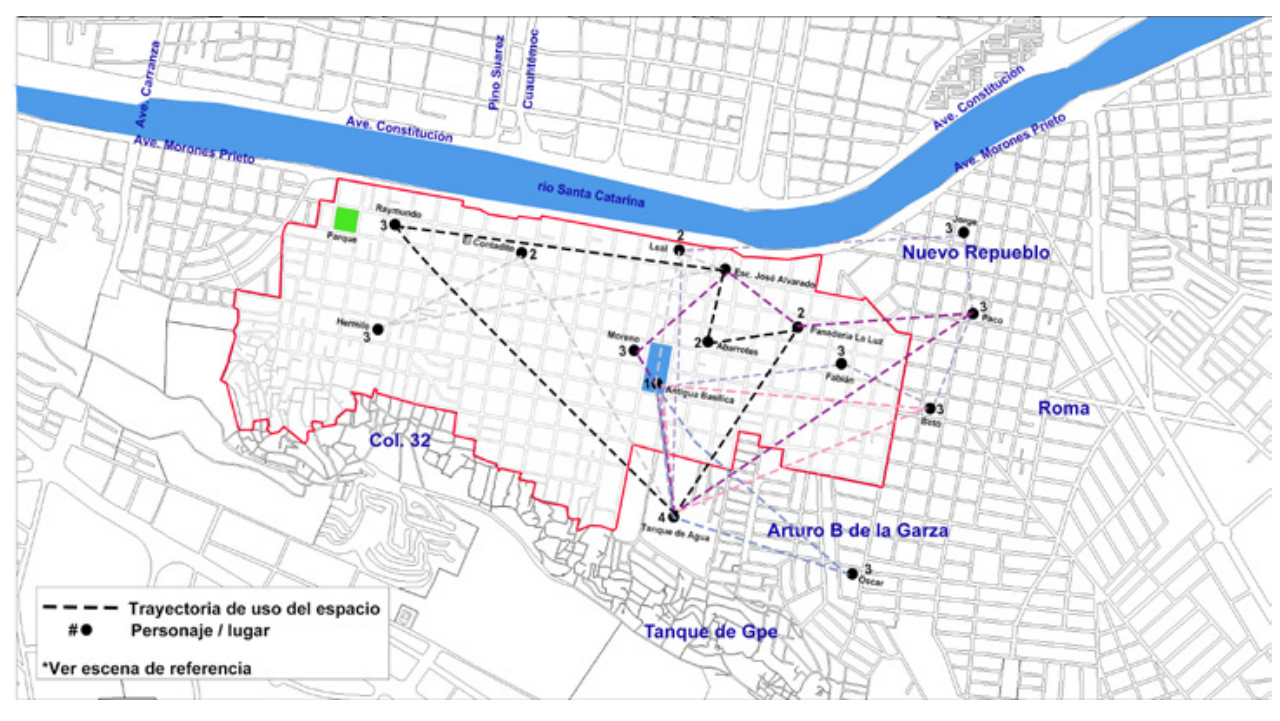

Figura 2. Graficación del origen de exclusión espacial.

Fuente: autora.

El primer mapa muestra que los habitantes de la Independencia hacían uso del espacio completo, pues mediante los relatos se expone que el fútbol era considerado un deporte de unión, ya que la explanada de la antigua basílica fungía como punto de reunión (1), y al terminar los partidos, los habitantes acudían a las tiendas cercanas a tomar un refresco (2). Varios de los jugadores vivían en colonias aledañas, por lo que la actividad de jugar fútbol en la Independencia se extendía a más de tres colonias alrededor (3). Con la construcción de la nueva basílica, los habitantes se vieron obligados a buscar otro espacio para continuar con sus torneos vecinales, $y$ adoptaron el tanque de agua como su nueva cancha (4). 
Transformación 1: Las canchas en el río

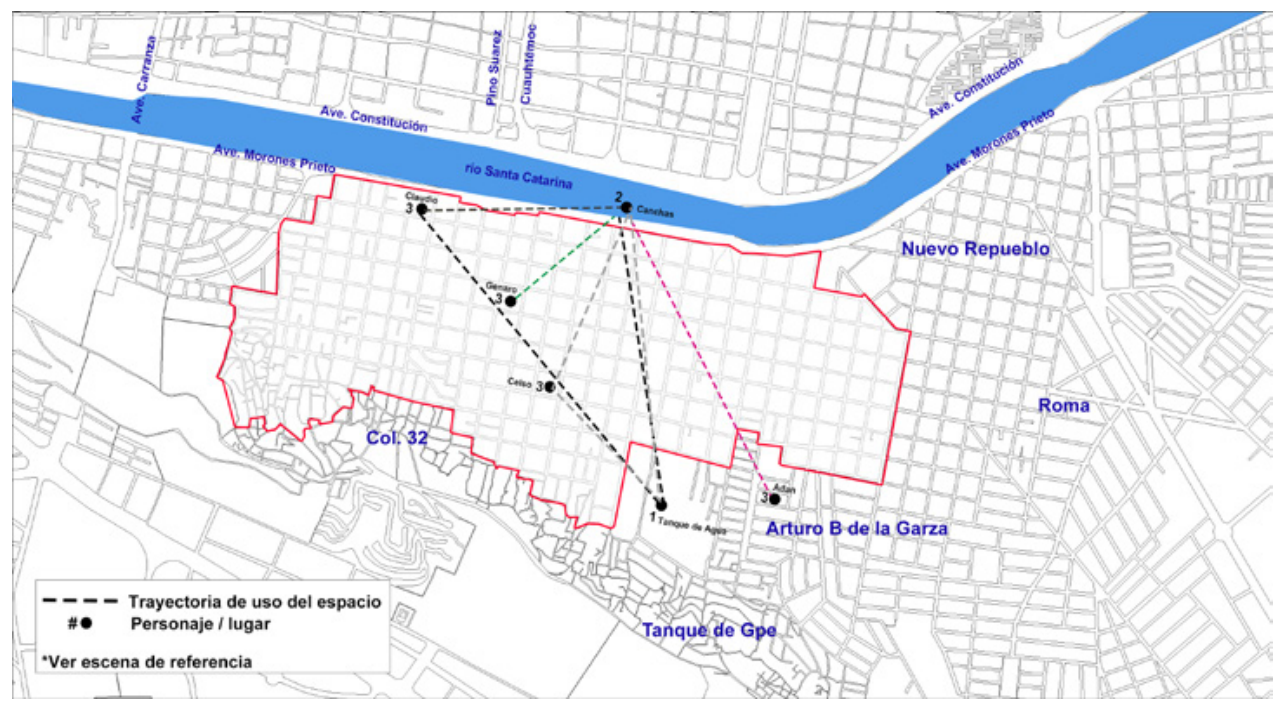

Figura 3. Graficación de la transformación 1 de exclusión espacial.

Fuente: autora.

El mapa de transformación 1 muestra otras fuerzas de la trayectoria, cuando los habitantes fueron desplazados del tanque de agua (1) al río Santa Catarina (2), donde continuaron jugando futbol y reuniéndose; sin embargo, muchos de los jugadores (3) decidieron ya no continuar en el equipo a causa de las malas condiciones de las canchas. Posteriormente, las canchas quedaron totalmente destruidas por el huracán Gilberto, por lo que nuevamente los habitantes tuvieron que buscar otro lugar para jugar. 


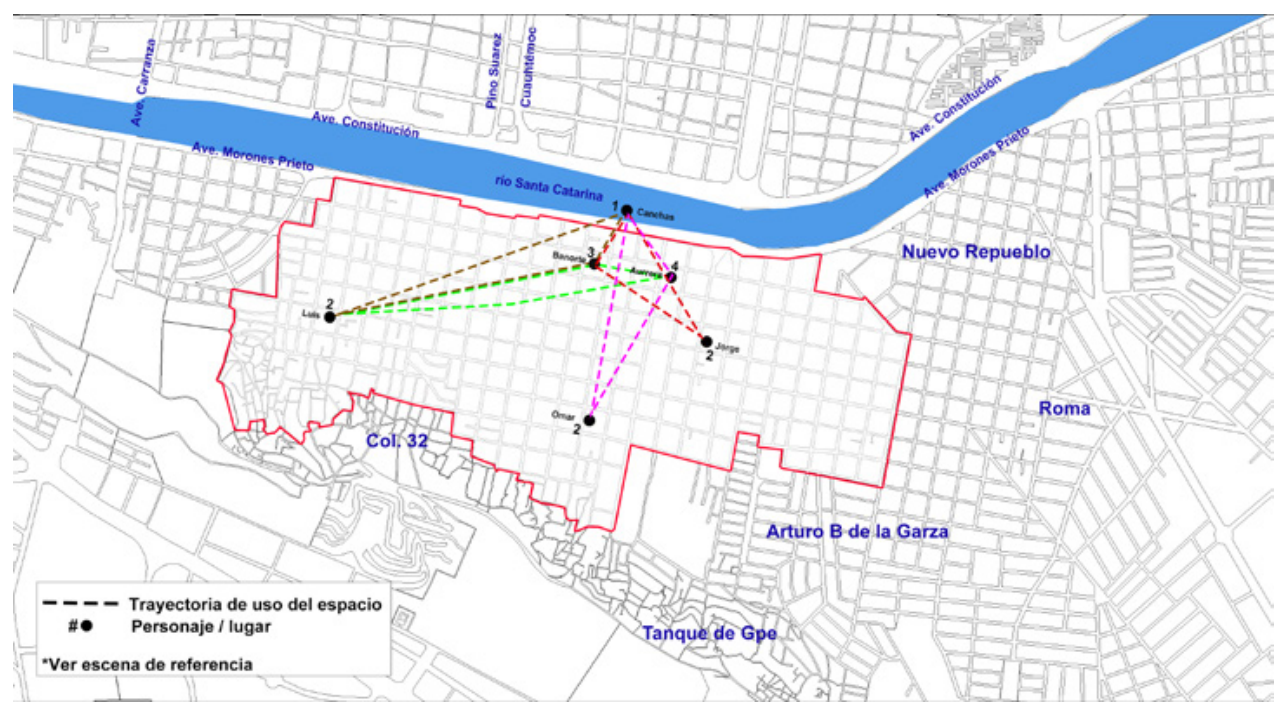

Figura 4. Graficación de la transformación 2 de exclusión espacial.

Fuente: autora.

En el mapa de transformación 2 se muestra la inundación del río Santa Catarina a causa del huracán Gilberto; posteriormente, el terreno fue rehabilitado por un desarrollador privado quien prohibió continuar jugando ahí (1). Los habitantes buscaron entonces nuevas alternativas para continuar practicando fútbol (2); sin embargo, los vecinos de colonias aledañas dejaron de interesarse en los torneos, ya que únicamente podían jugar después de las 4.00 pm, es decir, cuando el estacionamiento del banco (3) o de la bodega Aurrera (4) estaban cerrados. 


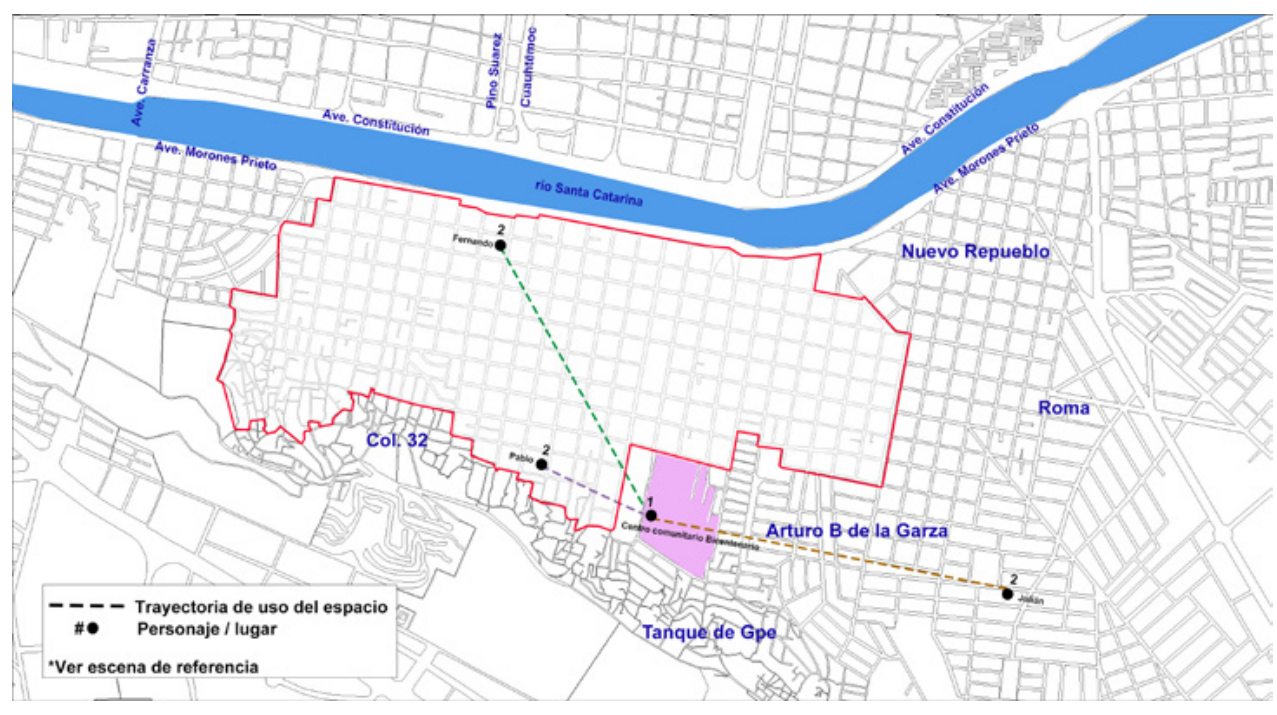

Figura 5. Graficación de la transformación 3 de exclusión espacial.

Fuente: autora.

En el último mapa (transformación 3), el territorio de la Independencia se transforma a una zona casi sin uso público. A pesar de que se construyó el Centro Comunitario Bicentenario (1), los habitantes terminaron por quedarse en casa a 'recrear' los antiguos juegos de fútbol a través de la televisión (2).

\section{Dibujando la exclusión espacial. Conclusiones y resultados}

Los mapas anteriores muestran que los habitantes de la Independencia fueron desplazados como resultado del cambio de uso en la zona. Así, las fuerzas (figura 6) que se identifican en la Independencia son: en el origen, se jugaba fútbol en el santuario (fuerza 1); después se trasladaron al terreno donde se localizaba el tanque de agua (fuerza 2); posteriormente se fueron al río Santa Catarina (fuerza 3), y años más tarde utilizaron el estacionamiento del Aurrera (fuerza 4). Después utilizaron 
el estacionamiento del banco para jugar (fuerza 5), pero al colocarle barda a los estacionamientos y restringir los horarios buscaron otro lugar; sin embargo, las canchas del río se volvieron privadas (fuerza 6) y se construyó el Centro Comunitario Bicentenario, pero con restricción de horario de uso (fuerza 7). Por último, los habitantes se quedaron en su casa para ver los partidos (fuerza 8).

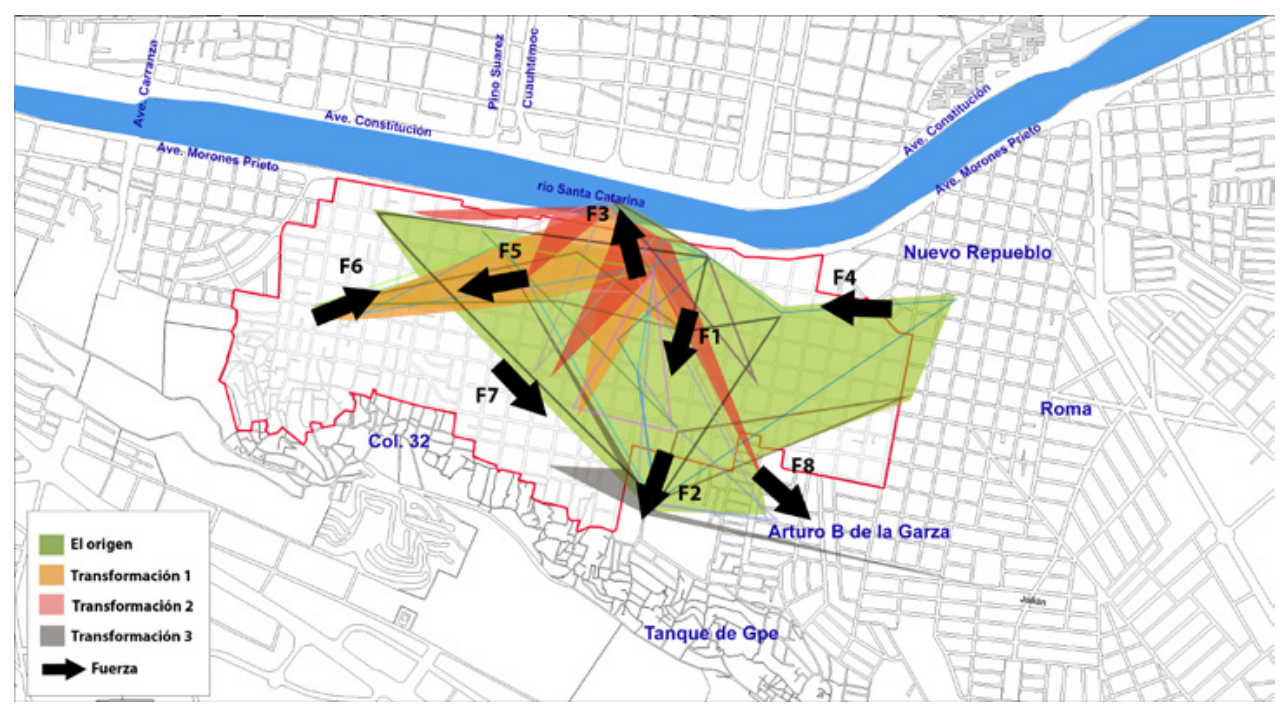


Los primeros esquemas de exclusión espacial muestran que las fuerzas que originan los diferentes procesos de exclusión se pueden integrar en nodos o niveles; en ese sentido, cada uno de los nodos constituye un peldaño que apunta hacia la expulsión. En consecuencia, la exclusión no puede ser considerada como un elemento estático, sino que cambia y se modifica de acuerdo con las fuerzas presentes. El primer nodo, de desplazamiento espacial, expresa el nivel más bajo de exclusión, y muestra cómo los habitantes son obligados a moverse hacia otro lado. El desplazamiento espacial involucra las dinámicas socio-espaciales que alejan a los habitantes de un territorio, obligándolos a cambiar de lugar para realizar sus actividades cotidianas. El nodo de desplazamiento se integra por un primer nivel de cambio de uso; un segundo nivel de arquitectura monumental invasiva; un tercer nivel de impacto de desplazamiento; y un cuarto nivel de gentrificación.

El segundo nodo corresponde a la marginalización espacial, que se define como la imposibilidad de residir en espacios sanos, capaces de brindar infraestructura básica, redes de conexiones viales y espacios de calidad. La limitación del espacio impacta de manera directa en el disfrute de las condiciones urbanas, provocando desventajas geográficas dentro de una dinámica urbana. El nodo de marginalización espacial se integra por un primer nivel que constituye el polígono de pobreza; un segundo nivel dado por la mala calidad ambiental; un tercer nivel que involucra la falta de espacios al aire libre; un cuarto nivel que implica la estigmatización del contexto inmediato; un quinto nivel de conectividad nula; y un sexto nivel dado por la falta de infraestructura.

El tercer nodo, de expulsión espacial, se liga a un proceso de destierro que tiene como objetivo erradicar a alguien de un territorio, es decir, no dejarlo vivir allí. La expulsión espacial se convierte en el nivel más alto de exclusión, y cada uno de los niveles muestra procesos en los que los habitantes terminan por perder el territorio donde se encuentran, o incluso la vida. El nodo de expulsión espacial se integra por un primer nivel de explotación de los recursos naturales; un segundo nivel de violación de los derechos urbanos; un tercer nivel de personas que viven en la calle; y un cuarto nivel dado por los desaparecidos. 


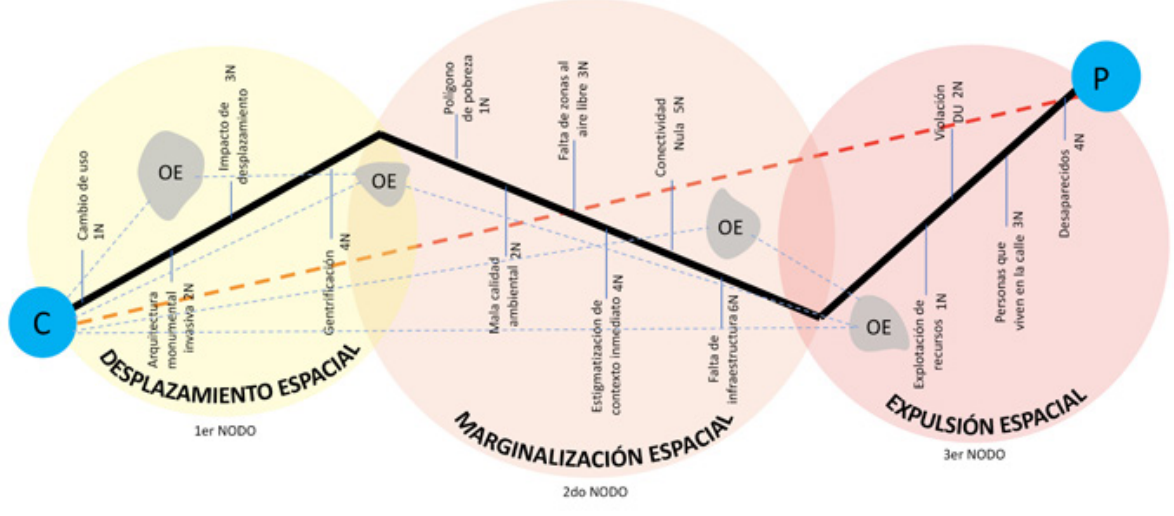

TRAYECTORIA DE EXCLUSIÓN ESPACIAL

Figura 7. Propuesta de trayectoria de la exclusión espacial.

Fuente: autora.

El dibujo sin duda se convierte en una herramienta de representación, por lo que las cartografías aquí propuestas buscan exponer las fuerzas espaciales que configuran la trayectoria de exclusión: como ejemplos se mencionan la prohibición de uso del espacio, la búsqueda de otro lugar, la colocación de barreras, la privatización, entre otros. Los esquemas realizados en la colonia Independencia muestran que el cambio de uso se convierte en el primer nivel de la trayectoria, lo que provoca un desplazamiento de sus habitantes; de esta manera, ellos perciben la pérdida del territorio experimentada durante varios años. Dibujar mapas no convencionales permite identificar otras caras del fenómeno urbano-arquitectónico, dando como resultado otra manera de representar la exclusión; en un futuro, se pretende que esta propuesta de esquematización forme parte de una guía, mediante la cual sea posible identificar todos aquellos lugares que han sido excluidos espacialmente, es decir, muchas historias invisibles que podrían revelarse. 


\section{REFERENCIAS BIBLIOGRÁFICAS}

Bessis, S. (s.f.). De la exclusión social a la cohesión social. París: Unesco.

Brenner, N. (2014). Implosions / Explosions. Towards a study of planetary urbanization. Berlin: JOVIS.

(2016). La explosión de lo urbano. ¿Qué es la teoría urbana crítica?. Chile: ARQ Ediciones.

De Mattos, C. (2007). Globalización, negocios inmobiliarios y transformación urbana. Revista Nueva Sociedad, 212, 82-96. Recuperado de: http://nuso.org/media/articles/downloads/3481_1.pdf

(2010). Globalización y metamorfosis metropolitana en América Latina. De la ciudad a lo urbano generalizado. Revista de Geografía Norte Grande, 47, 81-104.

Castells, M. (2006). La era de la información (vol. 3). Economía, sociedad y cultura. Fin de milenio. Madrid: Alianza.

Cepal (1998). La exclusión social de los grupos pobres en Chile. Santiago de Chile: Cepal.

Foucault, M. (1984). De los espacios otros (Des espaces autres). Architecture, Mouvement, Continuité, 5, 46-49. 
Lenoir, R. (1974). Les exclus: un français sur dix. París: Seuil.

Link, F. (2010). Globalización, vulnerabilidad y riesgo en la nueva configuración socio-territorial del trabajo en el área metropolitana de Santiago (Tesis doctoral). Pontificia Universidad Católica de Chile.

Mumford, L. (1989). The city in history. USA: Harcourt.

Padilla, D. (2019). Los espacios otros en las ciudades latinoamericanas. Redefinición de la inclusión desde la exclusión espacial (Tesis doctoral). Universidad Autónoma de Nuevo León, México.

Robles, F. (1999). Los sujetos y la cotidianeidad. Elementos para una micro sociología de lo contemporáneo. Concepción: Ed. Sociedad Hoy.

Saniz, J. (1990). El dibujo de arquitectura. España: Nerea.

Sassen, S. (2014). Expulsion: brutality and complexity in the global economy. USA: The Belknap Press of Harvard, University Press.

Soja, E. (2008). Postmetrópolis. Estudios críticos sobre las ciudades y las regiones. Madrid: Traficante de sueños. 